\title{
Fine-scale sampling unveils diazotroph patchiness in the South Pacific Ocean
}

\author{
Mar Benavides $\mathbb{D}^{1 凶}{ }^{凶}$, Louis Conradt ${ }^{1}$, Sophie Bonnet ${ }^{1}$, llana Berman-Frank ${ }^{2}$, Stéphanie Barrillon ${ }^{1}$, Anne Petrenko ${ }^{1}$ and Andrea Doglioli ${ }^{1}$
}

(c) The Author(s) 2021

Diazotrophs are important contributors to nitrogen availability in the ocean. Oceanographic cruise data accumulated over the past three decades has revealed a heterogeneous distribution of diazotroph species at regional to global scales. However, dynamic finescale physical structures likely affect the distribution of diazotrophs at smaller spatiotemporal scales. The interaction between finescale ocean dynamics and diazotrophs remains poorly understood due to typically insufficient spatiotemporal sampling resolution and the lack of parallel detailed physical studies. Here we show the distribution of five groups of diazotrophs in the South Pacific at an unprecedented resolution of 7-16 km. We find a patchy distribution of diazotrophs, with each group being differentially affected by parameters describing fine-scale physical structures. The observed variability in species abundance and distribution would be masked by a coarser sampling resolution, highlighting the need to consider fine-scale physics to resolve the distribution of diazotrophs in the ocean.

ISME Communications (2021)1:3; https://doi.org/10.1038/s43705-021-00006-2

The surface ocean is constantly stirred by currents that swirl and mix different seawater masses creating a dynamic mosaic of biogeochemical properties. ${ }^{1}$ Numerical modeling and satellite data show that "fine-scale" structures such as filaments and eddies (with typical spatiotemporal scales of 1-100 km and days-weeks) impact the distribution of phytoplankton and carbon export in the ocean. ${ }^{2-4}$ While these remote approaches provide synoptic views at large spatial scales, at-sea sampling remains imperative to resolve the diversity, metabolism and trophic interactions of microbes at finer scales. Yet, the typical spatiotemporal sampling resolution is too coarse to resolve fine-scale processes. ${ }^{5}$

Understanding the effect of fine-scales on biogeochemically relevant microbes is of particular importance. Dinitrogen $\left(\mathrm{N}_{2}\right)$ fixers or "diazotrophs" provide a significant source of bioavailable nitrogen to the ocean. ${ }^{6}$ Diazotrophs may accumulate in anticyclonic eddies, ${ }^{7,8}$ where eddy pumping deepens isopycnals impoverishing surface waters in inorganic nitrogen presumably favoring diazotroph growth. ${ }^{9}$ However, diazotrophs also accumulate in cyclonic eddies where low nutrient concentrations are attributed to wind-driven Ekman pumping. ${ }^{10}$ Such complex interactions between fine-scale physics and diazotrophs cannot be understood from satellite data alone.

Diazotrophs have a variable tolerance to biogeochemical conditions. For example, photosynthetic cyanobacteria such as Trichodesmium and UCYN-B abound in oligotrophic (sub)tropical waters, while UCYN-A's distribution spans the tropics to polar seas. ${ }^{6}$ Non-cyanobacterial diazotrophs cannot photosynthesize, and thus are regulated by different drivers to obtain carbon and energy. ${ }^{11}$ With such divergent physiologies, it is unlikely that different diazotrophs respond to fine-scale forcing similarly. Resolving these ambiguities requires coupling fine-scale physical measurements and diazotroph activity/abundance data at high spatiotemporal resolution. The vast majority of published diazotroph data were obtained at locations $\sim 160 \mathrm{~km}$ apart (median distance between stations in the diazotroph database ${ }^{12}$ ). Robidart et al. ${ }^{13}$ quantified diazotrophs with an ecogenomic sensor drifting over a single eddy at a resolution of $\sim 30 \mathrm{~km}$. More recently, Tang et al. $^{14}$ showed underway diazotroph activity/abundance data with $\sim 18 \mathrm{~km}$ resolution, but the effect of fine-scale physics was not taken into account.

Here we demonstrate the fine-scale distribution of diazotrophs in three zones of intense fine-scale activity in the South Pacific (TONGA cruise doi: 10.17600/18000884; Fig. 1). Each zone was selected for high-resolution sampling according to satellite and Lagrangian product maps received onboard on a daily basis. ${ }^{15}$ Maps included absolute dynamic topography (ADT), used to compute geostrophic velocities; finite-size Lyapunov exponents (FSLE), which depict transport barriers created by currents that can represent ecological boundaries; and the Okubo-Weiss parameter $(\mathrm{OW})$, which distinguishes vorticity-dominated from straindominated zones (e.g., eddies vs. non-eddies) (Supplementary Information; Table S1; Fig. S1). These parameters are thus useful to quantify fine-scale structures and to study their covariability with plankton distribution [e.g., ${ }^{4}$ ]. Planktonic biomass was collected with an automated filtration system at an unprecedented resolution of $7-16 \mathrm{~km}$. DNA extracted from the filters was used to quantify five diazotroph groups (Trichodesmium, UCYN-A1, UCYN-B, UCYN-C, and Gamma A) by quantitative PCR targeting the nifH gene, and, only in zone 3 nutrient concentrations and $\mathrm{N}_{2}$ fixation rates were also measured (Supplementary Information).

Our results reveal a patchy distribution of diazotrophs, driven by a heterogeneous effect of fine-scale physical parameters on each

\footnotetext{
${ }^{1}$ Aix Marseille Univ, Université de Toulon, CNRS, IRD, MIO UM 110, Marseille, France. ${ }^{2}$ Department of Marine Biology, Leon H. Charney School of Marine Sciences, University of
} Haifa, Mt. Carmel, Haifa, Israel. ${ }^{\times}$email: mar.benavides@ird.fr

Received: 21 October 2020 Revised: 17 February 2021 Accepted: 22 February 2021

Published online: 25 March 2021 

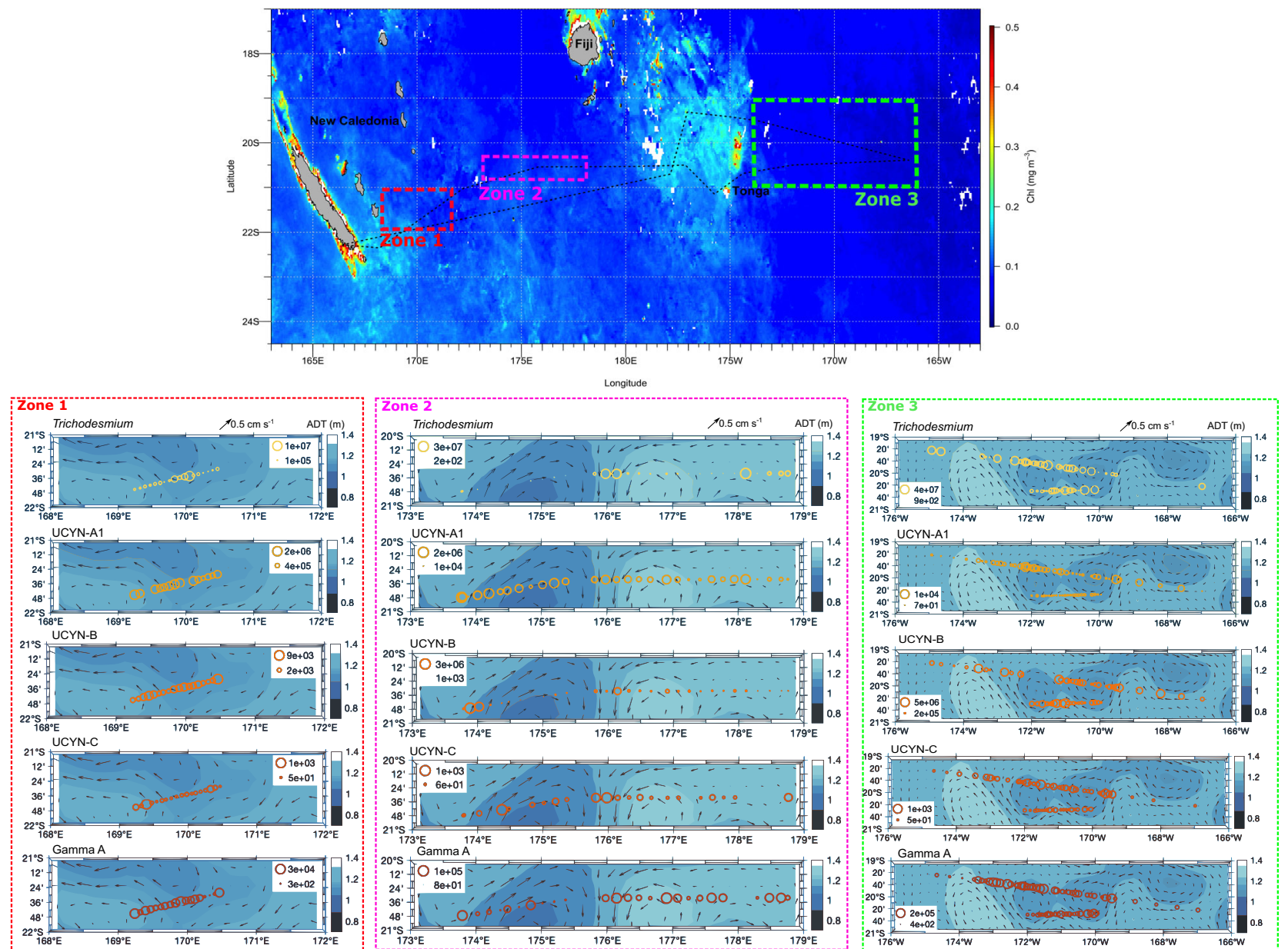

Fig. 1 Fine-scale resolution abundance of diazotrophs along three selected sampling zones. The top image shows a chlorophyll MODIS composite averaged for November 2019 at a resolution of $4 \mathrm{~km}$ and the location of the three selected sampling zones. The three lower panels (in dotted squares) show the abundance of diazotrophs (Trichodesmium, UCYN-A1, UCYN-B, UCYN-C, and Gamma) in each selected zone as nifH gene copies per liter of seawater. Diazotroph abundances ( $n$ ifH gene copies $\mathrm{I}^{-1}$ ) are superimposed on absolute dynamic topography (ADT, color scale) and geostrophic velocity (arrows). ADT data were retrieved for each zone on 2nd, 4th and 22nd November 2019 for zones 1 , 2, and 3 , respectively.

a)

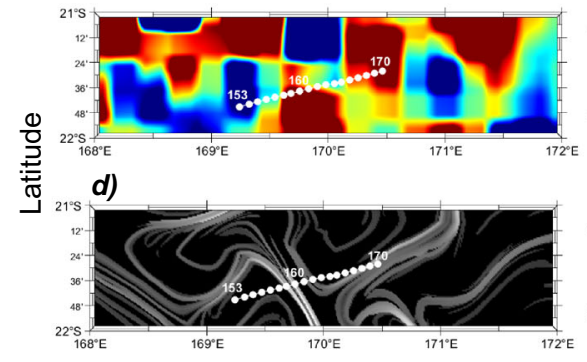

b)

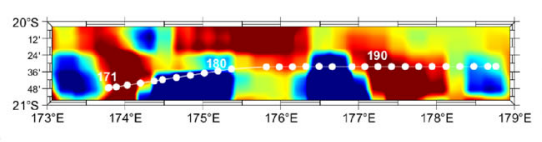

e)

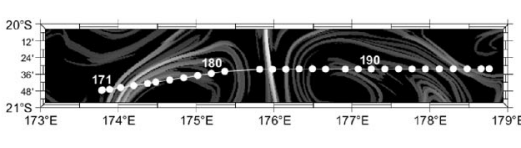

c)

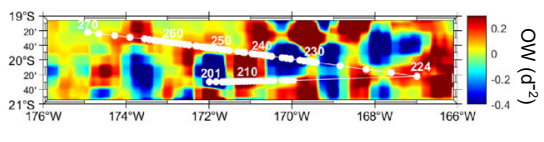

f)

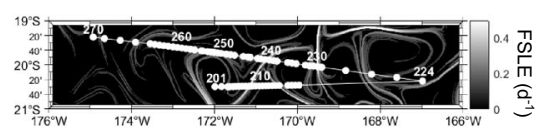

Longitude

Fig. 2 Lagrangian diagnostics parameters. a-c show values of the Okubo-Weiss (OW) in zones 1, 2, and 3, respectively. d-f show values of finite Lyapunov finite size Lyapunov exponents (FSLE) in zones 1, 2, and 3, respectively. White dots represent sampling locations, station numbers are also shown in white font.

group (Fig. 1; Fig. S2; Table S2). Trichodesmium correlated positively with ADT (Fig. 1; Fig. S2; Table S2) and accumulated at positive-negative OW transition and high FSLE regions located at $\sim 170^{\circ} \mathrm{E}, 176^{\circ} \mathrm{E}$, and $171^{\circ} \mathrm{W}$ in zones 1,2 and 3, respectively; Fig. 2). A particularly striking accumulation of Trichodesmium was observed at the convergence of two counter-rotating eddies in zone 2 (maximum $3 \times 10^{7}$ gene copies $\mathrm{I}^{-1}$; Fig. 1), coinciding with high FSLE values (Fig. 2) and a steep change in temperature (Fig. S3). The concentration of Trichodesmium at fronts depicted by high FSLE is likely linked to intracellular gas-vesicles providing them positive buoyancy. ${ }^{16}$ Previous concentrations of Trichodesmium along FSLE ridges uncoupled from significant $\mathrm{N}_{2}$ fixation rates have been interpreted as "passive" accumulations, i.e. finescale dynamics affecting their distribution but not their activity. ${ }^{17}$ 
UCYN-A1 were negatively related to FSLE (Table S2) and to Trichodesmium (Figs. S2 and S4), in agreement with the antagonistic biogeographic trends of these two diazotrophs witnessed at larger spatial scales. ${ }^{12}$ In comparison to other groups, the distribution of UCYN-A1 and UCYN-B was more spatially homogeneous and independent of fine-scales (Fig. S2). They were instead positively correlated to phosphate concentrations (Fig. S5), suggesting an "active" response to nutrient inputs induced by fine-scale dynamics ${ }^{9}$ ). These unicellular groups have a large surface area:volume ratio allowing for efficient nutrient utilization and higher growth rates than Trichodesmium, ${ }^{6}$ which could explain their faster response to limiting nutrient inputs induced by fine-scale dynamics. UCYN-C were significantly related to both ADT and FSLE (Table S2), but were the least abundant group (Fig. 1), likely due to their presumed coastal origin. ${ }^{6}$ Finally, Gamma A were significantly related to ADT (Table S2) and accumulated in frontal zones with high FSLE (Fig. 1), which agrees with their apparent particle-attached lifestyle. ${ }^{18}$

Although relatively high concentrations of phosphate were measured east of $\sim 175^{\circ} \mathrm{W}$ (Fig. S6), they sustained only moderate $\mathrm{N}_{2}$ fixation rates (1-5 nmol $\mathrm{N} \mathrm{I}^{-1} \mathrm{~d}^{-1}$; Fig. S6) likely due to a scarcity of iron east of the Tonga volcanic arc. ${ }^{19} \mathrm{~N}_{2}$ fixation rates correlated positively with Trichodesmium and negatively with UCYN-B (Fig. S5). Temperature and nutrients are typically invoked to define diazotroph biogeography on regional/global scales. ${ }^{12}$ These factors were remarkably homogeneously distributed in zone 3 (Figs. S6-7), and did not vary significantly according to fine-scale parameters (Fig. S7). Yet, diazotroph abundance revealed high spatial variability at the fine-scale in zone 3 (Fig. 1). Such variability would have gone unseen at a coarser resolution, stressing the role of fine-scale dynamics in diazotroph distribution.

The patchiness observed likely responds to a combination of bottom-up and top-down interactions between diazotrophs' competitors, predators and their biogeochemical environment. Understanding the controls imposed by fine-scales on other biotic and abiotic drivers will enhance our understanding of current and future diazotroph distribution and role in supplying new nitrogen to the ocean.

\section{REFERENCES}

1. Kavanaugh, M. T. et al. Seascapes as a new vernacular for pelagic ocean monitoring, management and conservation. ICES J. Mar. Sci. 73, 1839-1850 (2016).

2. Klein, P. \& Lapeyre, G. The oceanic vertical pump induced by mesoscale and submesoscale turbulence. Ann. Rev. Mar. Sci. 1, 351-375 (2009).

3. Lehahn, Y., D'Ovidio, F. \& Koren, I. A satellite-based lagrangian view on phytoplankton. Dyn. Ann. Rev. Mar. Sci. 10, 99-119 (2017).

4. d'Ovidio, F., De Monte, S., Alvain, S., Dandonneau, Y. \& Levy M. Fluid dynamical niches of phytoplankton types. Proc. Natl. Acad. Sci. 107, 18366-18370 (2010).

5. Lévy, M., Ferrari, R., Franks, P. J. S., Martin, A. P., \& Rivière, P. Bringing physics to life at the submesoscale. Geophys. Res. Lett. 39 (2012).

6. Zehr, J. P. \& Capone, D. G. Changing perspectives in marine nitrogen fixation. Science (80-) 368, eaay9514 (2020).

7. Fong, A. A. et al. Nitrogen fixation in an anticyclonic eddy in the oligotrophic North Pacific Ocean. ISME J 2, 663-676 (2008).

8. Davis, C. S. \& McGillicuddy, D. J. Transatlantic abundance of the $\mathrm{N}_{2}$-fixing colonial cyanobacterium Trichodesmium. Science (80-) 312, 1517-1520 (2006).

9. Benavides, M., Robidart, J. Bridging the spatiotemporal gap in diazotroph activity and diversity with high-resolution measurements. Front. Mar. Sci. 7, https://www. frontiersin.org/articles/10.3389/fmars.2020.568876/full (2020).

10. Olson, E. et al. Mesoscale eddies and Trichodesmium spp. distributions in the southwestern North Atlantic. J Geophys. Res. Ocean 120, 1-22 (2015).
11. Bombar, D., Paerl, R. W., \& Riemann, L. Marine non-cyanobacterial diazotrophs: moving beyond molecular detection. Trends Microbiol. 24, 916-927 (2016).

12. Luo, Y.-W. et al. Database of diazotrophs in global ocean: abundance, biomass and nitrogen fixation rates. Earth Syst. Sci. Data 4, 47-73 (2012).

13. Robidart, J. C. et al. Ecogenomic sensor reveals controls on $\mathrm{N}_{2}$-fixing microorganisms in the North Pacific Ocean. ISME J 8, 1175-1185 (2014).

14. Tang, W. et al. New insights into the distributions of nitrogen fixation and diazotrophs revealed by high-resolution sensing and sampling methods. ISME J. 14, 2514-2526 (2020).

15. Petrenko, A. A. et al. A review of the LATEX project: mesoscale to submesoscale processes in a coastal environment. Ocean Dyn 67, 513-533 (2017).

16. Guidi, L. et al. Does eddy-eddy interaction control surface phytoplankton distribution and carbon export in the North Pacific Subtropical Gyre? J. Geophys. Res. Biogeosci. 117 (2012)

17. Palter, J. B. et al. High $\mathrm{N}_{2}$ fixation in and near the Gulf Stream consistent with a circulation control on diazotrophy. Geophys Res Lett 47, e2020GL089103 (2020).

18. Cornejo-Castillo, F. M., \& Zehr, J. P. Intriguing size distribution of the uncultured and globally widespread marine non-cyanobacterial diazotroph Gamma-A. ISME J., 15, 124-128 (2020).

19. Bonnet, S., Caffin, M., Berthelot, H., \& Moutin, T. Hot spot of $\mathrm{N}_{2}$ fixation in the western tropical South Pacific pleads for a spatial decoupling between $\mathrm{N}_{2}$ fixation and denitrification. Proc. Natl. Acad. Sci. 114, E2800-E2801 (2017).

\section{ACKNOWLEDGEMENTS}

This study was funded by the projects TONGA (ANR-18-CE01-0016, LEFE-CyBER, Fondation A-Midex and Flotte Océanographique Française) to S.B. and C. Guieu, DEFINE (LEFE-CyBER) to M.B., and OASIS (Thomas Jefferson Fund) to S. T. Wilson and M.B. The development of SPASSO is supported by TOSCA/CNES, the EU program Copernicus Academy and the SIP OSU PYTHEAS. L.C. was funded by a Master degree internship from TONGA A-Midex. The authors would like to thank the crew and technical staff of R/V L'Atalante as well as the scientists that participated in sample acquisition and equipment installation onboard (C. Lory, K. Sellegri, and F. Gazeau), and sample analyses in the lab (S. Nunige, O. Grosso, A. Torremocha). The MODIS chlorophyll image used in Fig. 1 is a courtesy of J. Uitz. The authors greatly acknowledge the OMICS platform at the Mediterranean Institute of Oceanography (Marseille, France) for access to their facilities.

\section{COMPETING INTERESTS}

The authors declare no competing interests.

\section{ADDITIONAL INFORMATION}

Supplementary information The online version contains supplementary material available at https://doi.org/10.1038/s43705-021-00006-2.

Correspondence and requests for materials should be addressed to M.B.

Reprints and permission information is available at http://www.nature.com/ reprints

Publisher's note Springer Nature remains neutral with regard to jurisdictional claims in published maps and institutional affiliations.

\section{(i)}

Open Access This article is licensed under a Creative Commons Attribution 4.0 International License, which permits use, sharing, adaptation, distribution and reproduction in any medium or format, as long as you give appropriate credit to the original author(s) and the source, provide a link to the Creative Commons license, and indicate if changes were made. The images or other third party material in this article are included in the article's Creative Commons license, unless indicated otherwise in a credit line to the material. If material is not included in the article's Creative Commons license and your intended use is not permitted by statutory regulation or exceeds the permitted use, you will need to obtain permission directly from the copyright holder. To view a copy of this license, visit http://creativecommons. org/licenses/by/4.0/. 